\title{
Nonlinear Dynamic Response of an Axially Functionally Graded (AFG) Beam Resting on Nonlinear Elastic Foundation Subjected to Moving Load
}

https://doi.org/10.1515/nleng-2018-0051

Received January 6, 2018; revised June 1, 2018; accepted June 7, 2018.

Abstract: In recent years, structures made of Functionally Graded materials (FGMs) are used in industries due to the continuously compositional variation of the constituents in FGMs along different directions. In order to develop FGMs, nonlinear vibration analysis to study dynamic behavior is needed. This study proposes nonlinear vibration analysis of a simply supported axially functionally graded (AFG) beam subjected to a moving harmonic load as an Euler-Bernoulli beam utilizing Green's strain tensor. Axial variation of material properties of the beam is based on the power law. The governing equations of motion are derived via Hamilton's principle. The Galerkin's method is implemented to reduce the nonlinear partial differential equations of the system to a number of nonlinear ordinary differential equations. He's variational method is applied to obtain approximate analytical expressions for the nonlinear frequency and the nonlinear dynamic response of the AFG beam. The effect of some parameters such as the power index and stiffness coefficients, among others, on the nonlinear natural frequency has been investigated. The influence of above mentioned parameters as well as the velocity of the moving harmonic load on the nonlinear dynamic response has been studied. The results indicate that these parameters have a considerable effect on both nonlinear natural frequency and response amplitude.

Keywords: Axially functionally graded material. Nonlinear vibration analysis. Moving harmonic load. Nonlinear elastic foundation

Mehdi Alimoradzadeh, Department of Mechanical Engineering, Najafabad Branch, Islamic Azad University, Najafabad, Iran, E-mail: vib320@yahoo.com

*Corresponding Author: Mehdi Salehi, Department of Mechanical Engineering, Najafabad Branch, Islamic Azad University, Najafabad, Iran, E-mail: mehdi.salehi@pmc.iaun.ac.ir, Tel: +98 (31) 4229-1111

\section{Introduction}

Functionally graded materials (FGMs) are considered as one of the modern generation of composite materials. FGMs are characterized by continuous variation in composition over the volume of the material. This type of materials, which are usually a ceramic on one side shifting gradually to a pure metal on the other side, provide specific benefits on both of the constituents. They can be defined as inhomogeneous composites which are made from a mixture of two different materials, usually a metal and ceramic, with desired continuous variations of properties as a function of position along certain position. The continuously compositional variation of the constituents in FGMs along different directions is the great benefits of FGMs. This property offers a solution to damage problems due to shear stress in laminated composites, where two different materials are bonded together. Nowadays, structures made of FGMs have a great practical role in engineering and industrial fields [1-5].

Furthermore, nonlinear vibration analysis to study dynamic behavior at large amplitudes has been an interesting topic among researchers. N. D. Duc et al, studied an analytical approach on the nonlinear response of thick functionally graded circular cylindrical shells surrounded by elastic foundations subjected to mechanical and thermal loads [6]. By applying Galerkin method and using a proper stress function, explicit relations of thermal loaddeflection curves of the S-FGM shells were determined. They demonstrated that Elastic foundations enhance the stability and load-carrying capacity of S-FGM thick circular cylindrical shells. In another paper, an analytical model on nonlinear thermal dynamic behavior of imperfect functionally graded circular cylindrical shells eccentrically reinforced by outside stiffeners and surrounded on

Sattar Mohammadi Esfarjani, Department of Mechanical Engineering, Najafabad Branch, Islamic Azad University, Najafabad, Iran, E-mail: satar.iran@gmail.com 
elastic foundations using the Reddy's third order shear deformation shell theory in thermal environment developed [7]. It indicates that the stiffener system strongly impacts on the dynamic response of the FGM shells and the elastic foundations, outside stiffeners and temperature strongly affected the dynamic response of the SFGM circular cylindrical shells. N. D. Duc et al in another study, pursued an analytical approach to investigate the nonlinear dynamic response and vibration of imperfect functionally graded thick circular cylindrical shells resting on elastic foundation using the third order shear deformation shell theory [8]. It was shown that the temperature, geometrical parameters and imperfection have noticeable influence on the dynamic behavior of the SFGM thick circular cylindrical shell. Study on nonlinear dynamic response of higher order shear deformable sandwich functionally graded circular cylindrical shells with outer surface-bonded piezoelectric actuator on elastic foundations subjected to thermo-electro-mechanical loading is addressed in [9]. As reported by N. D. Duc [9], by applying the TSDT and stress function, the Galerkin and the Runge-Kutta techniques, the dynamic response of the thick piezoelectric S-FGM shells was determined. The amplitude-time curves for nonlinear dynamic analysis of the circular cylindrical shells were also obtained. Nonlinear vibration of FG beams based on the Euler-Bernoulli beam theory and von Kármán's geometric nonlinearity was studied by J. Ding et al. [10]. It was shown that increasing the parameter $\mathrm{m}$ will reduce the stiffness of $\mathrm{FG}$ beam, and consequently leads to an increase in the deflections and a reduction of the natural frequencies, unlike results for increasing Poisson's ratios, Span-to-depth ratios and Young's modulus ratio [10]. In a recent paper by N. D. Duc et al. [11], nonlinear dynamic analysis and vibration of eccentrically stiffened S-FGM elliptical cylindrical shells based on elastic foundations in thermal environments were investigated. Using stress function, Galerkin method, Runge-Kutta method and analytical approach, the nonlinear dynamic responses of the ES-SFGM eliptical shells were determined by explicit relations of material, geometrical parameters, temperature, outside stiffeners and elastic foundations parameters, so they could actively control dynamic response and vibration of the elliptical cylindrical shells by suitable pre-selection of these parameters [11]. Post-buckling and nonlinear free vibration analysis of geometrically imperfect functionally graded beams resting on nonlinear elastic foundation was investigated by Yaghoobi and Torabi [12]. Their study was within the framework of Euler-Bernoulli beam theory and vonKarman type displacement-strain relationship. They concluded that an increase in stiffness of linear and shear lay- ers of foundation decreases the frequency ratio of the imperfect FG beam. But, as the nonlinear foundation stiffness gets stronger, the frequency ratio and post-buckling load were progressively increased. Moreover, the imperfection was found to be significant when investigating the vibrations and post-buckling that take place in the vicinity of a deflected position. Nonlinear buckling and postbuckling of imperfect piezoelectric S-FGM circular cylindrical shells with metal-ceramic-metal layers in thermal environment using Reddy's third-order shear deformation shell theory were studied by N. D. Khoa et al. [13]. Numerical results were given to highlight the influences of geometrical parameters, material properties, imperfection, elastic foundations, temperature, electrical and mechanical loads on the nonlinear buckling and post buckling response of the piezoelectric S-FGM shells [13]. In [14], nonlinear response of a shear deformable S-FGM shallow spherical shell with ceramic-metal-ceramic layers resting on an elastic foundation in a thermal environment was investigated. It was observed that the nonlinear response of the S-FGM spherical shell is complex and greatly influenced by the material and geometric parameters and inplane restraint [14]. In another paper, thermal buckling analysis of FGM sandwich truncated conical shells reinforced by FGM stiffeners resting on elastic foundations using FSDT were investigated by N. D. Duc et al. [15]. It was shown that the critical thermal buckling load of FGM structure under both uniform temperature rise and linear temperature distribution across the shell thickness was lower than that of pure ceramic conical shells and higher than the pure metallic conical shells [15]. In [16] an analytical approach to large amplitude vibration and post-buckling of functionally graded beams resting on non-linear elastic foundation was developed through variational iteration method. Results indicated that the influence of linear and shear layers stiffness is to weaken the non-linear behavior of the FG beam, whereas the effect of the non-linear foundation stiffness was to harden the beam response [16]. Simsek et.al. investigated the influence of material distribution, velocity of the moving load and excitation frequency on the dynamic response of an AFG beam excited by a moving load [17]. It was observed that the above-mentioned effects play significant role in the dynamic behavior of the AFG beam [17]. In [18], large amplitude free vibration behavior of AFG thin tapered beam with various taper profile and material gradation was investigated by $\mathrm{H}$. Lohar et al. Backbone curves of parabolic tapered AFG beam for CC, CF, CS, SS boundary conditions are supplied at given taper parameter and spring stiffness. For all combinations of the system parameters, hardening type of nonlinearity was observed [18]. Nonlinear vibration and post-buckling 
analysis of beams made of functionally graded materials (FGMs) resting on nonlinear elastic foundation subjected to thermo-mechanical loading were studied by Yaghoobi et al. [19]. Results showed that the thermal loading has a significant effect on the vibration and post-buckling response of FG beams [19]. In [20], the first-order shear deformation theory was used to derive theoretical formulations illustrating the nonlinear dynamic response of functionally graded porous plates under thermal and mechanical loading supported by a Pasternak elastic foundation. $\mathrm{Nu}$ merical results illustrate the influence of geometrical configurations, volume faction index, porosity, elastic foundation properties, mechanical and thermal loads on the nonlinear dynamic response of the plates [20]. He [21] described a new kind of analytical technique for nonlinear problems called Variational Iteration Method (VIM) and used to give approximate solutions for some well-known nonlinear problems. He and $\mathrm{Wu}$ [22] reviewed trends and developments in the use of the VIM and its applications to nonlinear problems arising in various engineering applications. Rafei et al. [23] applied the VIM to nonlinear oscillators with discontinuities and showed that the VIM is an effective and convenient method leading to high accuracy solutions in the first iteration. Ke et al. [24] investigated the nonlinear free vibrations of FG beams based on Euler-Bernoulli beam theory and von Karman geometric nonlinearity employing the direct numerical integration and Runge Kutta methods. The effects of material property distribution and different end supports on nonlinear dynamic behavior are discussed showing different vibration behavior due to presence of quadratic nonlinearity. Lai et al. [25] derived accurate analytical solutions for large amplitude vibrations of thin FG beams in accordance with the Euler-Bernoulli beam theory and the von Karman type geometric nonlinearity. Ansari et al. [26, 27] studied vibration of a finite Euler-Bernoulli beam traversed by a moving load; the solution was obtained using the Galerkin method in conjunction with the Multiple Scales Method.Ding et al. [28] introduce an investigation of the convergenceof the Galerkin method for the dynamic response of a uniform beam resting on a nonlinear foundation with viscous damping subjected to a moving concentrated load. Abdelghany et al. [29] obtained the dynamic response of non-uniform Euler-Bernoulli simply supported beam. The beam is subjected to moving load and rested on a nonlinear viscoelastic foundation.

In this paper, non-linear dynamic response of an $\mathrm{Ax}$ ially Functionally Graded (AFG) Euler-Bernoulli simply supported beam is obtained. The beam subjected to moving harmonic load and rested on a nonlinear elastic foundation. The lack of considerable contribution in existing papers to nonlinear vibration analysis of AFG beams with such a support and loading condition motivated this paper. The influence of power index, linear and non-linear stiffness of foundation and the velocity of passing load on free vibration and non-linear dynamic response is be studied. Considering the effect of these whole parameters on nonlinear response of an AFG beam can provide complimentary information in the field to clarify the nonlinear behavior of such systems.

\section{Governing equations}

Consider a straight Euler-Bernoulli Axially Functionally Graded (AFG) beam of length $\mathrm{L}$ in $\mathrm{X}$ direction with rectangular cross-section of width $b$ and thickness $h$ in $Y$ and $Z$ direction, respectively. The beam is resting on nonlinear elastic foundation, Fig. 1 and subjected to moving harmonic load $q(x, t)$.

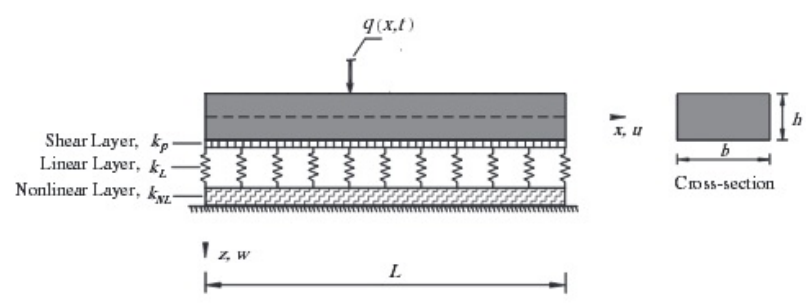

Fig. 1: AFG beam based on a three-layered nonlinear elastic foundation [30]

The reaction force of the elastic foundation acting on the beam can be expressed as [31]:

$$
p(x, t)=K_{L} w(x, t)+K_{N L} w^{3}(x, t)+K_{S} \frac{\partial^{2} w(x, t)}{\partial x^{2}}
$$

Where $p(x, t)$ distributed transverse force component, $K_{L}$ and $K_{N L}$ are the linear and nonlinear coefficient of elastic foundation, respectively, and $K_{S}$ stands for the coefficients of shear stiffness of the elastic foundation and $t$ is the time. It is assumed that material properties, i, e, Young, s modulus (E) , density $(\rho)$ of the AFG beam vary continuously through the length of the beam according to the power-law as follows [30]:

$$
\begin{aligned}
& E(x)=E_{R}+\left(E_{L}-E_{R}\right)\left(1-\frac{x}{L}\right)^{n} \\
& \rho(x)=\rho_{R}+\left(\rho_{L}-\rho_{R}\right)\left(1-\frac{x}{L}\right)^{n}
\end{aligned}
$$

Where $\mathrm{n}$ is the volume fraction exponent which dictate the material variations profile through the length of the 
beam and subscripts $L$ and $R$ refer to the left and the right end of the beam, respectively. The poisson's ratio is assume to be constant $(v=0)$ in this study. According to the Euler-Bernoully beam theory, axial and transverse displacements of an arbitrary point in the beam, i,e, $u$ and $\mathrm{w}$ along $\mathrm{X}$ and $\mathrm{Z}$ direction, respectively, can be expressed as [30]:

$$
\begin{gathered}
u_{x}(x, z, t)=u(x, t)-z \frac{\partial w(x, t)}{\partial x} \\
u_{z}(x, z, t)=w(x, t)
\end{gathered}
$$

Where $u(x, t)$ and $w(x, t)$ are the displacement components in the mid-plane along $X$ and $Z$ direction, respectively, and $\frac{\partial w(x, t)}{\partial x}$ is the rotation angle about Y-axis.

The strain energy of the beam in terms of the stress and the strains can be expressed as [32]:

$$
U_{s}=\int_{V} \sigma_{i j} \epsilon_{i j} d v
$$

Where $\sigma_{i j}$ is the stress tensor, $\epsilon_{i j}$ is the strain tensor. these tensors are given by:

$$
\sigma_{i j}=\lambda \epsilon_{k k} \delta_{i j}+2 \mu \epsilon_{i j}
$$

The nonlinear strain-displacement relations are given by Green's strain tensor as follows [33]:

$$
\epsilon_{i j}=\frac{1}{2}\left[\left(\frac{\partial u_{i}}{\partial x_{j}}+\frac{\partial u_{j}}{\partial x_{i}}\right)+\left(\frac{\partial u_{k}}{\partial x_{i}} \frac{\partial u_{k}}{\partial x_{j}}\right)\right], i, j, k=x, y, z
$$

Where $\lambda=\frac{E v}{(1+v)(1-2 v)}$ and $\mu=\frac{E}{2(1+v)}$ are the lame's constant. Substituting Eq (4) and Eq. (5) into Eq. (8) yields to:

$$
\epsilon_{x x}=\frac{\partial u(x, t)}{\partial x}+\frac{1}{2}\left(\frac{\partial w(x, t)}{\partial x}\right)^{2}-z \frac{\partial^{2} w(x, t)}{\partial x^{2}}
$$
to:

And substituting Eq. (7) and Eq. (9) into Eq. (6) yields

$$
\begin{aligned}
U_{s}= & \frac{1}{2} \int_{0}^{L}\left\{E(x) A\left[\left(\frac{\partial u}{\partial x}+\frac{1}{2}\left(\frac{\partial w(x, t)}{\partial x}\right)^{2}\right)^{2}\right]\right. \\
& \left.+E(x) I\left[\left(\frac{\partial^{2} w(x, t)}{\partial x^{2}}\right)^{2}\right]\right\} d x
\end{aligned}
$$

Where $A=b . h$ and $I=\frac{1}{12} b h^{3}$ are the cross-section and second moment of area of the beam, respectively.

The strain energy induced by the nonlinear elastic medium $u_{e l}$ can be written as [30]:

$$
u_{e l}=\int_{0}^{l}\left(\frac{1}{2} k_{L} w^{2}+\frac{1}{2} k_{p}\left(\frac{\partial w}{\partial x}\right)^{2}+\frac{1}{4} k_{N} w^{4}\right) d x
$$

The kinetic energy of the Euler-Bernoulli AFG beam (T), [34], and the external work (V) done by the moving harmonic load $q(x, t)=q_{0} \sin \omega_{0} t$,can be written down as follows:

$$
\begin{gathered}
T=\frac{1}{2} \int_{0}^{L} \rho(x) A\left[\left(\frac{\partial u(x, t)}{\partial t}\right)^{2}+\left(\frac{\partial w(x, t)}{\partial t}\right)^{2}\right] d x \\
V=\int_{0}^{L}[q(x, t) \delta(x-v t) w(x, t)] d x
\end{gathered}
$$

Where $\delta(x-v t)$ is the Dirac delta function used to deal with the moving concentrated harmonic load $q(x, t), q_{0}$ is the amplitude of the moving harmonic load, $\omega_{0}$ is the magnitude of the excitation frequency of the moving harmonic load and $v$ is the speed of the moving harmonic load.In order to derive the governing equation of motion of the AFG Euler-Bernoulli beam, resting on nonlinear elastic foundation and subjected to moving harmonic load, the Hamilton principle is utilized as [30]:

$$
\delta \int_{0}^{T}\left[T-\left(U_{s}+U_{e l}\right)+V\right] d t=0
$$

Substituting Eq. (10), Eq. (11), Eq. (12) and Eq. (13) into Eq. (14),the governing equations and the corresponding boundary conditions can be achived as:

$$
\begin{aligned}
& \frac{\partial}{\partial x}\left[E(x) A\left(\frac{\partial u}{\partial x}+\frac{1}{2}\left(\frac{\partial w}{\partial x}\right)^{2}\right)\right]=\rho(x) A \frac{\partial^{2} u}{\partial t^{2}} \\
& -\frac{\partial^{2}}{\partial x^{2}}\left[E(x)\left(I \frac{\partial^{2} w}{\partial x^{2}}\right]\right. \\
& +\frac{\partial}{\partial x}\left[E(x) A\left(\frac{\partial u}{\partial x}+\frac{1}{2}\left(\frac{\partial w}{\partial x}\right)^{2}\right)\right] \frac{\partial w}{\partial x} \\
& +E(x) A\left[\frac{\partial u}{\partial x}+\frac{1}{2}\left(\frac{\partial w}{\partial x}\right)^{2}\right] \frac{\partial^{2} w}{\partial x^{2}}-k_{L} w \\
& -k_{N L} w^{3}+k_{s} \frac{\partial^{2} w}{\partial x^{2}}+q_{0} \delta(x-v t) \sin \omega_{0} t=\rho(x) A \frac{\partial^{2} w}{\partial t^{2}}
\end{aligned}
$$

The corresponding boundary conditions are defined at $x=0$ and $x=L$ as follows:

$$
\begin{gathered}
E(x) A\left(\frac{\partial u}{\partial x}+\frac{1}{2}\left(\frac{\partial w}{\partial x}\right)^{2}\right)=0 \quad \text { or } \quad \delta u=0 \\
E(x)(I) \frac{\partial^{2} w}{\partial x^{2}}=0 \quad \text { or } \quad \delta\left(\frac{\partial w}{\partial x}\right)=0
\end{gathered}
$$




$$
\begin{aligned}
& -E(x) A\left(\frac{\partial u}{\partial x}+\frac{1}{2}\left(\frac{\partial w}{\partial x}\right)^{2}\right) \frac{\partial w}{\partial x}+\frac{\partial}{\partial x}\left[E(x)(I) \frac{\partial^{2} w}{\partial x^{2}}\right] \\
& -k_{s} \frac{\partial w}{\partial x}=0 \text { or } \delta w=0
\end{aligned}
$$

As seen from Eq. (15) and Eq. (16), the governing equations are coupled with respect to the displacements $u$ and $\mathrm{w}$. thus in order to reduced the equations to a single equation in terms of $w$, the in-plane inertia can be neglected, [35, 36] and Eq. (16) can be rewritten as:

$$
\frac{\partial}{\partial x}\left[E(x) A\left(\frac{\partial u}{\partial x}+\frac{1}{2}\left(\frac{\partial w}{\partial x}\right)^{2}\right)\right]=0
$$

Integration of Eq. (20),with respect to $x$ gives

$$
E(x) A\left(\frac{\partial u}{\partial x}+\frac{1}{2}\left(\frac{\partial w}{\partial x}\right)^{2}\right)=C
$$

or

$$
\frac{\partial u}{\partial x}=\frac{c}{E(x) A}-\frac{1}{2}\left(\frac{\partial w}{\partial x}\right)^{2}
$$

Where $c$ is the integration constant to be calculated with respect to the boundary conditions. It is assumed that the AFG beam has immovable supports in the axial direction. Thus the boundary conditions related to the axial motion are expressed as [32]:

$$
u(l, t)=u(0, t)=0
$$

Integrating both side of Eq. (22), from 0 to $L$ together with the above boundary conditions yields to:

$$
C=\frac{A}{2 L} \int_{0}^{L}\left(E(x)\left(\frac{\partial w}{\partial x}\right)^{2}\right) d x
$$

The governing equation is derived in terms of $\mathrm{w}$ by substituting Eq. (21), In to Eq. (16) as follows

$$
\begin{aligned}
& \frac{\partial^{2}}{\partial x^{2}}\left[E(x)(I) \frac{\partial^{2} w}{\partial x^{2}}\right]-\left[\frac{A}{2 L} \int_{0}^{L}\left(E(x)\left(\frac{\partial w}{\partial x}\right)^{2}\right) d x\right] \frac{\partial^{2} w}{\partial x^{2}} \\
& +k_{L} w+k_{N L} w^{3}-k_{S} \frac{\partial^{2} w}{\partial x^{2}}+\rho(x) A \frac{\partial^{2} w}{\partial t^{2}} \\
& =q_{0} \delta(x-v t) \sin \omega_{0} t
\end{aligned}
$$

\section{Solution of the problem}

\subsection{Galerkin's method}

In order to apply the Galerkin method, the displacement function $\mathrm{w}(\mathrm{x}, \mathrm{t})$ can be expanded into finite series as follows [31]:

$$
w(x, t)=\alpha(x) \beta(t)
$$

Where $\beta(t)$ is the unknown time-dependent coefficient to be determined and $\alpha(x)$ is the basis (test) function which must satisfy the kinematic boundary conditions. The following test function can be chosen for simply supported (pin-pin) boundary conditions [31]:

$$
\alpha(x)=\sin \left(\frac{\pi}{L} x\right)
$$

Substituting the approximate solution in Eq. (26) into Eq. (25), then multiplying both sides of resulting equation with $\alpha(x)$ integrating over the domain $(0, L)$ yields to:

$$
\ddot{\beta}(t)+\epsilon_{1} \beta(t)+\epsilon_{2} \beta^{3}(t)=F_{0} \sin \omega_{0} t \sin \frac{\pi v t}{L}
$$

Where $\ddot{\beta}(t)$ is the second derivative of $\beta(t)$ with respect to time. The coefficients $\epsilon_{1}, \epsilon_{2}$ and $F_{0}$ in Eq. (28), can be expressed as:

$\epsilon_{1}=\frac{\int_{0}^{L}\left\{I\left[\frac{\partial^{2} E(x)}{\partial x^{2}} \frac{\partial^{2} \alpha(x)}{\partial x^{2}}+E(x) \frac{\partial^{4} \alpha(x)}{\partial x^{4}}\right]+K_{L} \alpha(x)-K_{S} \frac{\partial^{2} \alpha(x)}{\partial x^{2}}\right\} \alpha(x) d x}{\int_{0}^{L} \rho(x) A \alpha^{2}(x) d x}$

$$
\begin{gathered}
\epsilon_{2}=\frac{\int_{0}^{L}\left\{K_{N L} \alpha^{3}(x)-g_{1} \frac{\partial^{2} \alpha(x)}{\partial x^{2}}\right\} \alpha(x) d x}{\int_{0}^{L} \rho(x) A \alpha^{2}(x) d x} \\
F_{0}=\frac{q_{0}}{\int_{0}^{L} \rho(x) A \alpha^{2}(x) d x}
\end{gathered}
$$

Where

$$
g_{1}=\frac{A}{2 L} \int_{0}^{L} E(x)\left(\frac{\partial \alpha(x)}{\partial x}\right)^{2} d x
$$

\subsection{Approximate analytical solution for nonlinear free vibration}

The beam is subjected to following initial conditions:

$$
\beta(0)=y, \frac{\partial \beta(0)}{\partial t}=0
$$

Where $y$ is the maximum vibration amplitude of the beam. The exact solution of nonlinear differential equation is very limited and very time consuming, for this reason, approximate methods are inevitable to solve nonlinear differential equations [31]. By using He's variational method [37], and omitting the forcing $F_{0}$, for free vibration analysis, Eq. (28) can be rewritten as follows:

$$
\ddot{\beta}(t)+f(t)=0
$$

Where

$$
f(t)=\epsilon_{1} \beta(t)+\epsilon_{2} \beta^{3}(t)
$$


Its variational formula can be readily obtain as follows [37]:

$$
J(\beta)=\int_{0}^{\frac{T}{4}}\left(-\frac{1}{2} \dot{\beta}^{2}+F(\beta)\right) d t
$$

Where $T$ is the period of the nonlinear oscillator and $\frac{\partial F}{\partial \beta}=$ $f$.

$$
J(\beta)=\int_{0}^{\frac{T}{4}}\left(-\frac{1}{2} \dot{\beta}^{2}+\frac{\epsilon_{1}}{2} \beta^{2}+\frac{\epsilon_{2}}{4} \beta^{4}\right) d t
$$

Assume that its approximate solution can be expressed as [37]:

$$
\beta(t)=y \cos \left(\omega_{n} t\right)
$$

Where $y$ and $\omega_{n}$ are the amplitude and nonlinear natural frequency of the nonlinear oscillator, respectively. By substituting Eq. (38) in to Eq. (37), and considering the transformation $\theta=\omega_{n} t$, one can obtain

$$
\begin{aligned}
& J\left(y, \omega_{n}\right) \\
& =\int_{0}^{\frac{\pi}{2}} \frac{1}{\omega_{n}}\left(-\frac{1}{2} y^{2} \omega_{n}{ }^{2}(\sin \theta)^{2}+\frac{\epsilon_{1}}{2} y^{2}(\cos \theta)^{2}+\frac{\epsilon_{2}}{4}\left\{y^{4}(\cos \theta)^{4}\right) d t\right.
\end{aligned}
$$

According to the Ritz method, the stationary conditions $\frac{\partial J}{\partial y}=0$ and $\frac{\partial J}{\partial \omega_{n}}=0$, should be satisfied in order to obtain $\omega_{n}$. However, this approach generally gives inaccurate results for nonlinear oscillators [37], and He [37],modified this conditions in to a simple form $\frac{\partial J}{\partial y}=0$. The stationary condition $\frac{\partial J}{\partial y}=0$, results in

$$
\begin{aligned}
& \frac{\partial J}{\partial y} \\
& =\frac{1}{\omega_{n}} \int_{0}^{\frac{\pi}{2}}\left(-y \omega_{n}{ }^{2}(\sin \theta)^{2}+\epsilon_{1} y(\cos \theta)^{2}+\epsilon_{2} y^{3}(\cos \theta)^{4}\right) d \theta \\
& =0
\end{aligned}
$$

After some mathematical amendment, Eq. (40), takes the following form

$$
\omega_{n}^{2}=\frac{\int_{0}^{\frac{\pi}{2}}\left(\epsilon_{1}(\cos \theta)^{2}+\epsilon_{2} y^{2}(\cos \theta)^{4}\right) d \theta}{\int_{0}^{\frac{\pi}{2}}\left((\sin \theta)^{2}\right) d \theta}
$$

The nonlinear natural frequency $\omega_{n}=\omega_{N L}$ can be found by performing the integral expression in Eq. (41), as follows:

$$
\omega_{N L}=\sqrt{\left(\epsilon_{1}+\frac{3}{4} \epsilon_{2} y^{2}\right)}
$$

\subsection{Approximate analytical solution for nonlinear forced vibration}

As previously discussed, the response of the AFG beam, resting on nonlinear elastic foundation under the action of moving harmonic load is assumed to be governed by the equation below:

$$
\begin{gathered}
\ddot{\beta}(t)+\epsilon_{1} \beta(t)+\epsilon_{2} \beta^{3}(t)=F_{0} \sin \omega_{0} t \sin \frac{\pi v t}{L} \\
\beta(0)=y, \quad \frac{\partial \beta(0)}{\partial t}=0
\end{gathered}
$$

its correction functional can be written down as follows [2]:

$$
\begin{aligned}
& \beta_{n+1}(t)=\beta_{n}(t) \\
& +\int_{0}^{t} \lambda\left[\frac{d^{2} \beta_{n}(\tau)}{d \tau^{2}}+\epsilon_{1} \beta_{n}(\tau)+\epsilon_{2} \beta_{n}{ }^{3}(\tau)-F_{0} \sin \omega_{0} \tau \sin \frac{\pi v \tau}{L}\right] d \tau
\end{aligned}
$$

Where $\lambda$ is lagrange multiplier. Making the above correction functional stationary and noticing that $\delta \beta(0)=0$ [2].

$$
\begin{aligned}
& \delta \beta_{n+1}(t)=\delta \beta_{n}(t) \\
& +\delta \int_{0}^{t} \lambda\left[\frac{d^{2} \beta_{n}(\tau)}{d \tau^{2}}+\epsilon_{1} \beta_{n}(\tau)+\epsilon_{2} \beta_{n}{ }^{3}(\tau)-F_{0} \sin \omega_{0} \tau \sin \frac{\pi v \tau}{L}\right] d \tau \\
& =0
\end{aligned}
$$

Yields to the following stationary conditions:

$$
\begin{gathered}
\frac{d^{2} \lambda(\tau)}{d \tau^{2}}+\epsilon_{1} \lambda(\tau)=0 \\
1-\frac{d \lambda(\tau)}{d \tau}=0, \text { at } \tau=t \\
\lambda(\tau)-0, \text { at } \tau=t
\end{gathered}
$$

The multiplier can be obtained as $\lambda(\tau)=$ $\frac{1}{\sqrt{\epsilon_{1}}} \sin \left(\sqrt{\epsilon_{1}}(\tau-t)\right)$, and the following variational iteration formula can be obtained:

$$
\begin{aligned}
& \beta_{n+1}(t)=\beta_{n}(t) \\
& +\frac{1}{\sqrt{\epsilon_{1}}} \int_{0}^{t} \sin \left(\sqrt{\epsilon_{1}}(\tau-t)\right)\left[\frac{d^{2} \beta_{n}(\tau)}{d \tau^{2}}+\epsilon_{1} \beta_{n}(\tau)+\epsilon_{2} \beta_{n}{ }^{3}(\tau)\right. \\
& \left.-F_{0} \sin \omega_{0} \tau \sin \frac{\pi v \tau}{L}\right] d \tau
\end{aligned}
$$

Assuming that its approximate solution has the form [2]:

$$
\beta_{0}(t)=y \cos \left(\sqrt{\epsilon_{1}} \alpha t\right)
$$


Where $\alpha\left(\epsilon_{2}\right)$ is a non-zero unknown function of $\epsilon_{2}$, with $\alpha(0)=1$, [2]. The substitution Of Eq. (50), in Eq. (43), result in the following residual:

$$
\begin{aligned}
R_{0}= & y \epsilon_{1}\left(\left(1-\alpha^{2}\right)+\frac{3 \epsilon_{2} y^{2}}{4 \epsilon_{1}}\right) \cos \left(\sqrt{\epsilon_{1}} \alpha t\right) \\
& +\frac{\epsilon_{2} y^{3}}{4} \cos \left(3 \sqrt{\epsilon_{1}} \alpha t\right)-F_{0} \sin \omega_{0} t \sin \frac{\pi v t}{L}
\end{aligned}
$$

Generally speaking, the residual Eq. (51), isn't equal to zero. the right- hand of Eq. (51), would have to vanish if $\beta_{0}(t)$ were to be a solution of Eq. (43).we may, however, at the least assure the vanishing of the factor of $\cos \left(\sqrt{\epsilon_{1}} \alpha t\right)$ by setting [2]:

$$
\alpha\left(\epsilon_{2}\right)=\sqrt{\left(1+\frac{3 \epsilon_{2}}{4 \epsilon_{1}} y^{2}\right)}
$$

Then by iteration formula (49), we obtain:

$$
\begin{aligned}
& \beta_{1}(t)=y \cos \left(\sqrt{\epsilon_{1}} \alpha t\right) \\
& +\frac{\epsilon_{2} y^{3}}{4 \epsilon_{1}\left(9 \alpha^{2}-1\right)}\left(\cos \left(3 \sqrt{\epsilon_{1}} \alpha t\right)-\cos \left(\sqrt{\epsilon_{1}} t\right)\right) \\
& +\frac{F_{0}}{2}\left(\frac{\cos \left(\frac{\pi v}{L}-\omega_{0}\right) t}{\epsilon_{1}-\left(\frac{\pi v}{L}-\omega_{0}\right)^{2}}-\frac{\cos \left(\frac{\pi v}{L}+\omega_{0}\right) t}{\epsilon_{1}-\left(\frac{\pi v}{L}+\omega_{0}\right)^{2}}\right)
\end{aligned}
$$

\section{Numerical results}

The properties of the AFG beam, foundation and the moving harmonic load are listed in Table 1.

\subsection{Nonlinear Free Vibration Results}

The nonlinear natural frequency $\omega_{N L}$ versus amplitude $y$ by changing the values of power-index $(\mathrm{n})$, nonlinear stiffness $\left(K_{N L}\right)$, linear stiffness $\left(K_{L}\right)$, and shear stiffness $\left(K_{S}\right)$ are shown in Figs. 2-5, respectively. As they are seen, by the increase of the value of power index, (Fig. 2), the nonlinear natural frequency of $\omega_{N L}$ is decrease and by the increase of the values of nonlinear stiffness $\left(K_{N L}\right)$, linear stiffness $\left(K_{L}\right)$, and shear stiffness $\left(K_{S}\right)$ in Figs. 3-5, respectively, the nonlinear natural frequency of $\omega_{N L}$ is increase.

\subsection{Results for nonlinear forced vibration}

The maximum deflection of $W_{\max },(x=L / 2)$ versus time $t$ by changing the values of power-index (n), velocity (v), nonlinear stiffness $\left(K_{N L}\right)$, linear stiffness $\left(K_{L}\right)$, and shear stiffness $\left(K_{S}\right)$ are shown in Figs. 6-10, respectively.

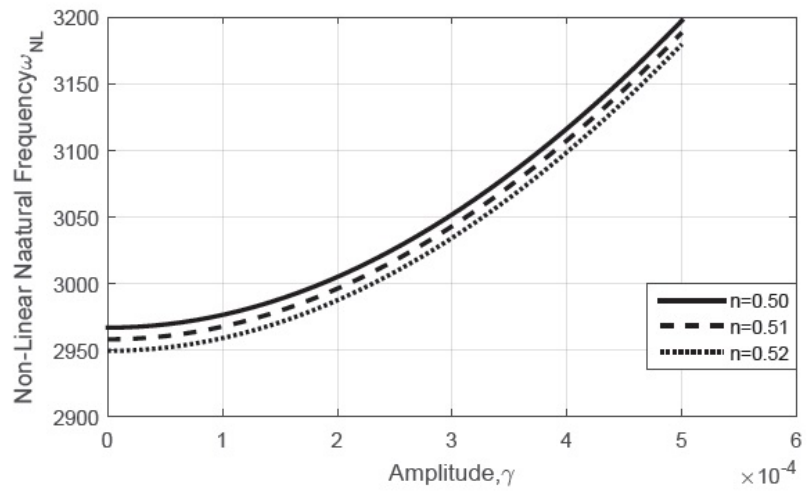

Fig. 2: Variations of $\omega_{N L}$ versus amplitude with respect to variations of $n$

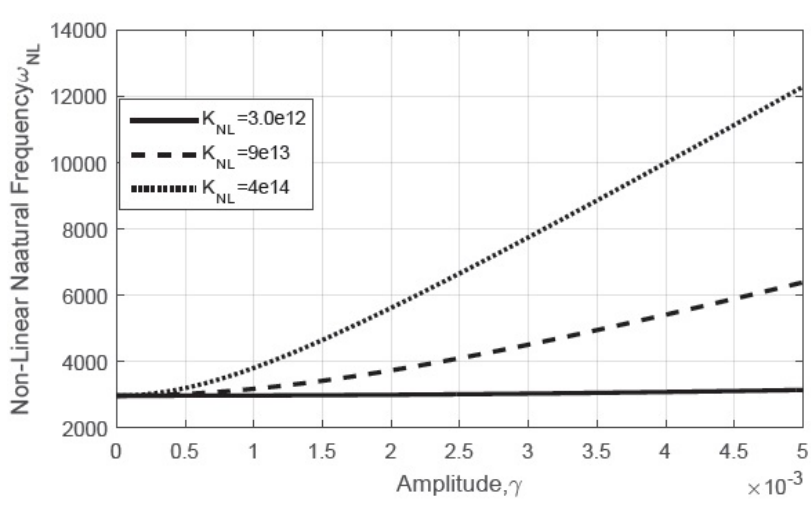

Fig. 3: Variations of $\omega_{N L}$ versus amplitude with respect to variations of $K_{N L}$

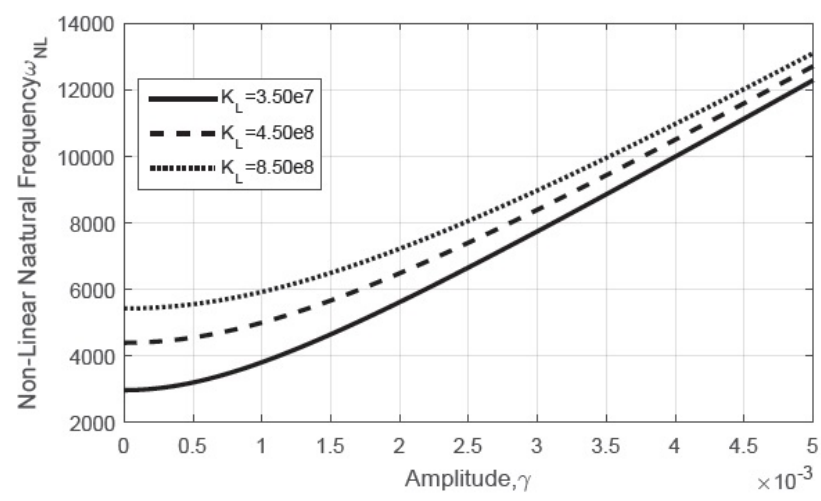

Fig. 4: Variations of $\omega_{N L}$ versus amplitude with respect to variations of $K_{L}$

As they are seen, by the increase of the value of power index, (Fig. 6), and velocity (Fig. 7), the maximum deflection of the system is increase. By the increase of the values of nonlinear stiffness (Fig. 8), the periodically of the system is reduce. Also by the increase of the values of linear stiffness (Fig. 9), and shear stiffness (Fig. 10), the maximum deflection of the system is decrease. 
Table 1: Properties of beam, foundation and load

\begin{tabular}{ccc}
\hline Item & Notation & Load \\
\hline Young's modulus at the left end (METAL) & $E_{L}$ & $210 \mathrm{GPa}$ \\
Young's modulus at the right end & $E_{R}$ & $393 \mathrm{GPa}$ \\
(CERAMIC) & $\rho_{L}$ & $7850 \mathrm{~kg} / \mathrm{m}^{3}$ \\
Mass density at the left end (METAL) & $\rho_{R}$ & $3960 \mathrm{~kg} / \mathrm{m}^{3}$ \\
Mass density at the right end (CERAMIC) & $A$ & $7.69 \times 10^{-3} \mathrm{~m}^{2}$ \\
Cross-sectional area & $I$ & $3.055 \times 10^{-5} \mathrm{~m}^{4}$ \\
Second moment of area & $L$ & $18 \mathrm{~m}$ \\
Length & $K_{L}$ & $3.5 \times 10^{7} \mathrm{~N} / \mathrm{m}^{2}$ \\
Mean (linear) stiffness & $K_{N L}$ & $4 \times 10^{14} \mathrm{~N} / \mathrm{m}^{4}$ \\
Nonlinear stiffness & $K_{S}$ & $3 \times 10^{7} \mathrm{~N} / \mathrm{m}^{2}$ \\
Shear stiffness & $q_{0}$ & $65 \times 10^{3}$ \\
Amplitude of the moving harmonic load & $\omega_{0}$ & $2955 \mathrm{rad} / \mathrm{s}$ \\
Excitation frequency & $\mathrm{v}$ & $10 \mathrm{~m} / \mathrm{s}$ \\
speed & $\mathrm{n}$ & 0.50 \\
Power index & $y$ & $0.005 \mathrm{~m}$ \\
Amplitude & & \\
\hline
\end{tabular}

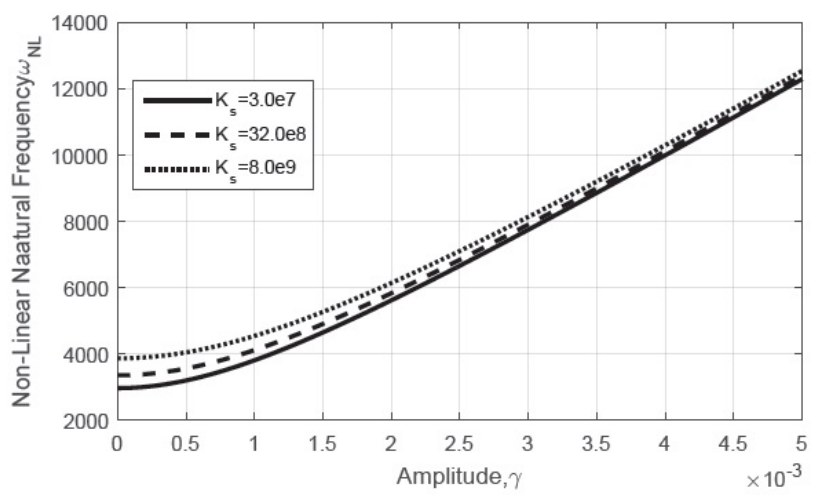

Fig. 5: Variations of $\omega_{N L}$ versus amplitude with respect to variations of $K_{S}$

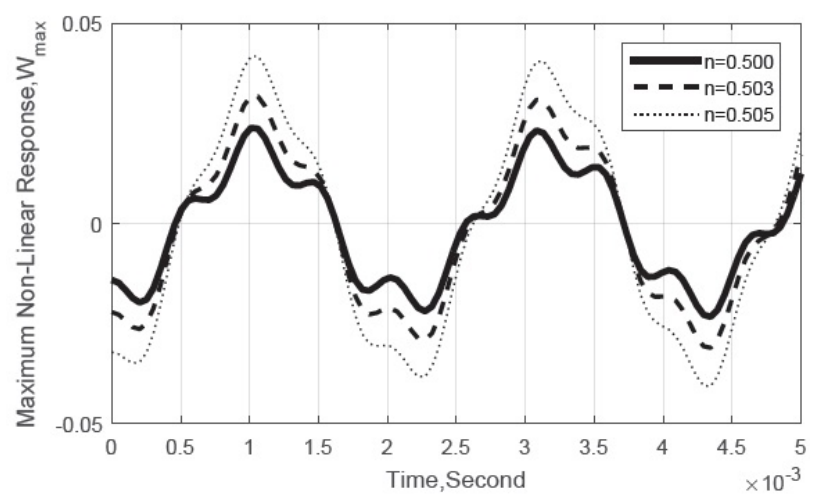

Fig. 6: The maximum deflection versus t with respect to variations of $n$

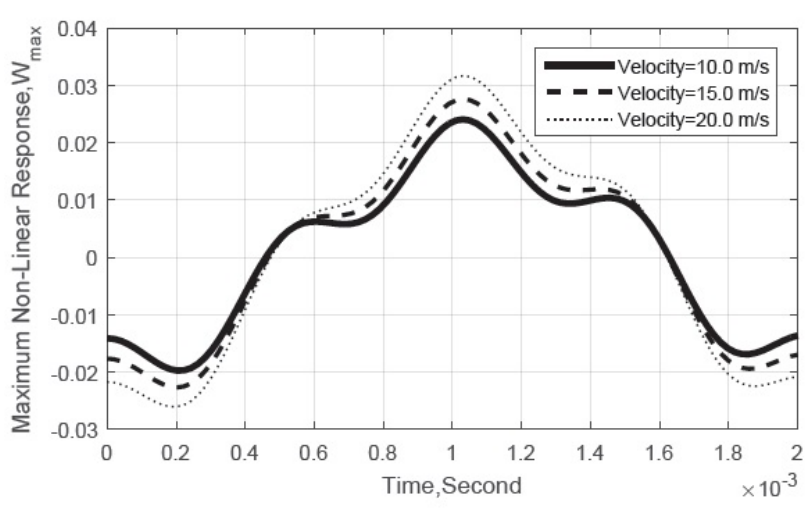

Fig. 7: The maximum deflection versus $t$ with respect to variations of $v$

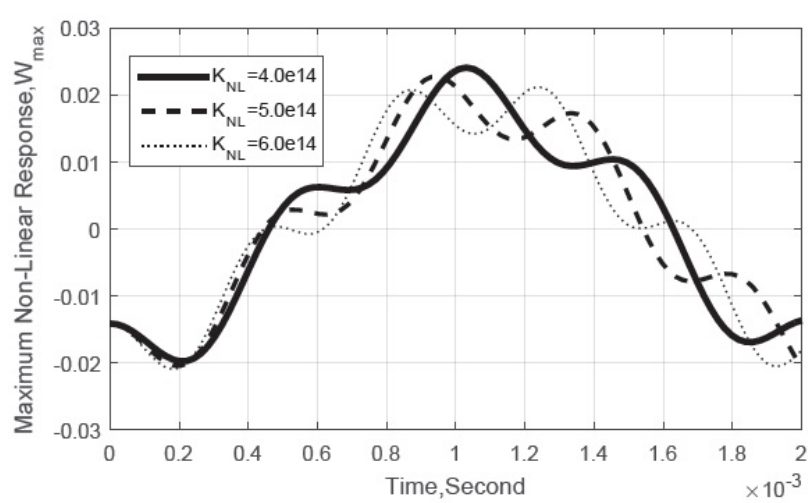

Fig. 8: The maximum deflection versus t with respect to variations of $K_{N L}$

\section{Conclusion}

In this paper, non-linear dynamic response of Axially Functionally Graded (AFG) material Euler-Bernoulli sim- 


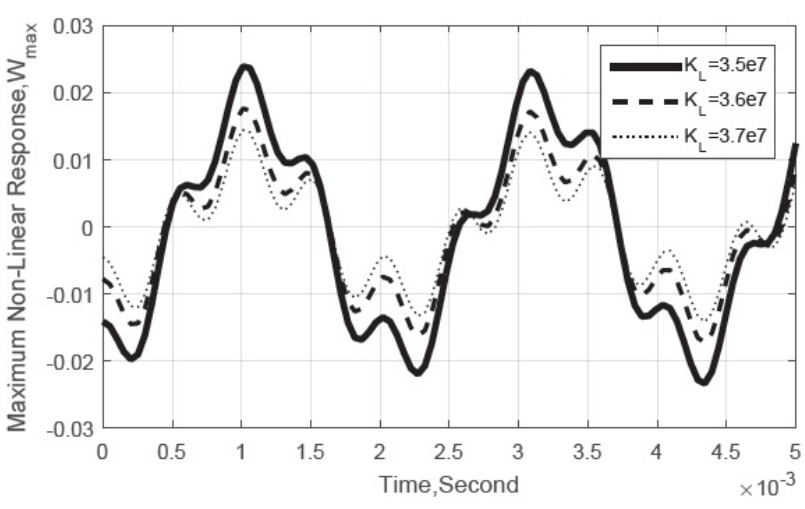

Fig. 9: The maximum deflection versus t with respect to variations of $K_{L}$

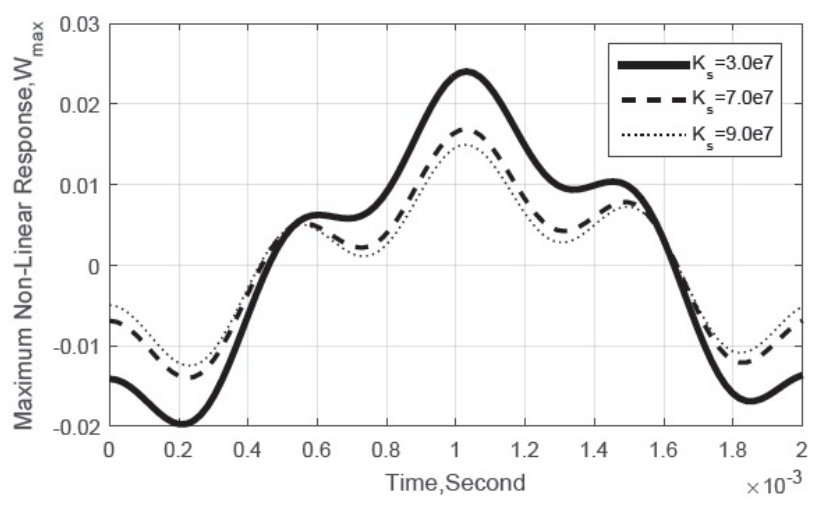

Fig. 10: The maximum deflection versus t with respect to variations of $K_{S}$

ply supported beam was obtained. The beams subjected to moving harmonic load and rested on a nonlinear elastic foundation. Also the influence of $\mathrm{n}$ (power index), $\mathrm{k} \_\mathrm{L}$ (linear stiffness), k_NL (non-linear stiffness)and v (velocity) on free vibration and non-linear dynamic response was studied. The results shown that in a nonlinear AFG Euler-Bernoulli beam resting on nonlinear elastic foundation and subjected to moving harmonic load, increasing of power index causes an increasing of maximum deflection (maximum dynamic response) and decreasing the nonlinear natural frequency. Increasing of linear stiffness coefficient and shear stiffness coefficient cause an increasing of nonlinear natural frequency and decreasing the maximum dynamic response (maximum deflection). Increasing of nonlinear stiffness coefficient cause an increasing the nonlinear natural frequency and decreasing periodically of the oscillation. Also increasing of velocity of the moving harmonic load cause an increasing of the maximum dynamic response

\section{Nomenclatures}

Young's modulus at the left end(METAL) $E_{L} \mathrm{GPa}$ Young's modulus at the right end(CERAMIC) $E_{R} \mathrm{GPa}$ Mass density at the left end(METAL) $\rho_{L} \mathrm{Kg} / \mathrm{m}^{3}$ Mass density at the right end(CERAMIC) $\rho_{R} \mathrm{Kg} / \mathrm{m}^{3}$ Cross-sectional area $A \mathrm{~m}^{2}$ Second moment of area $I \mathrm{~m}^{4}$

Length $L 18 \mathrm{~m}$ Mean (linear) stiffness $K_{L} \quad \mathrm{~N} / \mathrm{m}^{2}$ Nonlinear stiffness $K_{N L} \mathrm{~N} / \mathrm{m}^{4}$ Shear stiffness $K_{S} \quad \mathrm{~N} / \mathrm{m}^{2}$ Amplitude of the moving harmonic load $q_{0}-$ Excitation frequency $\omega_{0} \mathrm{rad} / \mathrm{s}$ speed $\mathrm{v} \mathrm{m} / \mathrm{s}$

Power index $\mathrm{n}-$

Amplitude $y \mathrm{~m}$

\section{References}

[1] Asghari M., Rahaeifard M., Kahrobaiyan M.H., Ahmadian M.T. The modified couple stress functionally graded Timoshenko beam formulation. Materials and design, 2011; 32: 1435-1443. doi: 10.1016/j.matdes.2010.08.046

[2] Zhong J., Fu Y., Chen Y., Li Y. Analysis of nonlinear dynamic responses for functionally graded beams resting on tensionless elastic foundation under thermal shock. Composite Structures, 2016; 142: 272-277 doi:10.1016/j. compstruct.2016.01.096

[3] Quan T.Q., Duc N. D. Nonlinear vibration and dynamic response of shear deformable imperfect functionally graded doublecurved shallow shells resting on elastic foundations in thermal environments. Journal of Thermal Stresses, 2016; 39(4): 437459. doi:10.1080/01495739.2016.1158601

[4] Thanh N. V., Khoa N. D., Tuan N .D., Tran P., Duc N. D. Nonlinear dynamic response and vibration of functionally graded carbon nanotube-reinforced composite (FG-CNTRC) shear deformable plates with temperature-dependent material properties and surrounded on elastic foundations. Journal of Thermal Stresses, 2017; 40(10): 1254-1274. doi:10.1080/0 1495739.2017.1338928

[5] Duc N. D. Nonlinear Static and Dynamic Stability of Functionally Graded Plates and Shells. Vietnam National University Press, Hanoi, 2014. ISBN: 9786046217275.

[6] Duc N. D., Thang P. T., Dao N. T., Tac H. V. Nonlinear buckling of higher deformable S-FGM thick circular cylindrical shells with metal-ceramic-metal layers surrounded on elastic foundations in thermal environment. Composite Structures, 2015; 121: 134141. doi: 10.1016/j.compstruct.2014.11.009

[7] Duc N. D. Nonlinear thermal dynamic analysis of eccentrically stiffened S-FGM circular cylindrical shells surrounded on elastic foundations using the Reddy's third-order shear deformation shell theory. European Journal of Mechanics A/Solids, 206; 58: 10-30. doi: 10.1016/j.euromechsol.2016.01.004

[8] Duc N. D., Tuan N. D., Tran P., Dao N. T., Dat N. T. Nonlinear dynamic analysis of Sigmoid functionally graded circular cylin- 
drical shells on elastic foundations using the third order shear deformation theory in thermal environments. International Journal of Mechanical Sciences, 2015; 101-102: 338-348. doi: 10.1016/j.ijmecsci.2015.08.018

[9] Duc N. D. Nonlinear thermo-electro-mechanical dynamic response of shear deformable piezoelectric sigmoid functionally graded sandwich circular cylindrical shells on elastic foundations. Journal of Sandwich Structures and Materials, 2018; 20(3): 351-378. doi: 10.1177/1099636216653266

[10] Ding J., Chu L., Xin L., Dui G. Nonlinear Vibration Analysis of Functionally Graded Beams Considering the Influences of the Rotary Inertia of the Cross Section and Neutral Surface Position. Mechanics Based Design of Structures and Machines, 2018; 46: 225-237. doi: 10.1080/15397734.2017.1329020

[11] Duc N. D., Nguyen P. D., Khoa N. D. Nonlinear dynamic analysis and vibration of eccentrically stiffened S-FGM elliptical cylindrical shells surrounded on elastic foundations in thermal environments. Thin-Walled Structures, 2017; 117: 178-189. doi: 10.1016/j.tws.2017.04.013

[12] Yaghoobi H., Torabi M. Post-buckling and nonlinear free vibration analysis of geometrically imperfect functionally graded beams resting on nonlinear elastic foundation. Applied Mathematical Modelling, 37 (2013), 8324-8340. doi: 10.1016/j.apm.2013.03.037

[13] Khoa N. D., Thiem H. T., Duc N. D. Nonlinear buckling and postbuckling of imperfect piezoelectric S-FGM circular cylindrical shells withmetal-ceramic-metal layers in thermal environment using Reddy's third-order shear deformation shell theory. Mechanics of Advanced Materials and Structures, 2017; 1-12. doi: 10.1080/15376494.2017.1341583

[14] Anh V. T. T., Duc N. D. Nonlinear response of a shear deformable S-FGM shallow spherical shell with ceramic-metalceramic layers resting on an elastic foundation in a thermal environment. Mechanics of Advanced Materials and Structures, 2016; 23(8): 926-934. doi: 10.1080/15376494.2015.1059527

[15] Duc N. D., Seung-Eock K., Chan D. Q. Thermal buckling analysis of FGM sandwich truncated conical shells reinforced by FGM stiffeners resting on elastic foundations using FSDT. Journal of Thermal Stresses, 2018; 41(3): 331-365. doi: 10.1080/01495739.2017.1398623

[16] Yaghoobi H., Torabi M. An analytical approach to large amplitude vibration and post-buckling of functionally graded beams rest on non-linear elastic foundation. Journal of Theoretical and Applied Mechanics, 2013; 51: 39-52.

[17] Simsek M., Kocatürk T., Akbas S .D. Dynamic behavior of an axially functionally graded beam under action of a moving harmonic load. Composite Structures, 2012; 94: 2358-2364. doi: 10.1016/j.compstruct.2012.03.020

[18] Lohar H., Mitra A., Sahoo S. Geometric nonlinear free vibration of axially functionally graded non-uniform beams supported on elastic foundation. Curved and Layered Structures, 2016; 3(1): 223-239. doi: 10.1515/cls-2016-0018.

[19] Yaghoobi H., Valipour M. S., Fereidoon A., Khoshnevisrad $P$. Analytical study on post-buckling and nonlinear free vibration analysis of FG beams resting on nonlinear elastic foundation under thermo-mechanical loadings using VIM. Steel and Composite Structures, 2014; 17: 753-776. doi: 10.12989/scs.2014.17.5.753

[20] Duc N. D., Quang V. D., Nguyen P. D., Chien T. M. Nonlinear Dynamic Response of Functional Graded Porous Plates on Elastic
Foundation Subjected to Thermal and Mechanical Loads. Journal of Applied and Computational Mechanics, 2018; (Articles in Press). doi: 10.22055/JACM.2018.23219.1151

[21] He J-H. Variational iteration method - a kind of non-linear analytical technique: some examples. Int J Nonliner Mech. 1999; 34: 699-708. doi: 10.1016/S0020-7462(98)00048-1

[22] He J-H, Wu X-H. Variational iteration method: new development and applications. Comput Math Appl, 2007; 54:881-894. doi: 10.1016/j.camwa.2006.12.083

[23] Rafei M, Ganji D, Daniali H, Pashaei H. The variational iteration method for nonlinear oscillators with discontinuities. J. Sound Vib. 2007; 305: 614-620. doi: 10.1016/j.jsv.2007.04.020

[24] Ke L-L, Yang J, Kitipornchai S. An analytical study on the nonlinear vibration of functionally graded beams. Meccanica, 2010; 45:743-752. doi: 10.1007/s11012-009-9276-1

[25] Lai S, Harrington J, Xiang Y, Chow K. Accurate analytical perturbation approach for large amplitude vibration of functionally graded beams. Int J Nonliner Mech, 2012; 47: 473-480. doi: 10.1016/j.ijnonlinmec.2011.09.019

[26] Ansari M, Esmailzadeh E, Younesian D. Internal-external resonance of beams on nonlinear viscoelastic foundation traversed by moving load. Nonlinear Dyn, 2010; 61: 163-182. doi: 110.1007/s11071-009-9639-0

[27] Ansari M, Esmailzadeh E, Younesian D. Frequency analysis of finite beams on nonlinear Kelvin-Voight foundation under moving loads. J. Sound Vib. 2011; 330:1455-1471. doi: 10.1016/j.jsv.2010.10.005

[28] Ding Hu, Chen Li-Qun, Yang Shao-Pu. Convergence of Galerkin truncation for dynamic response of finite beams on nonlinear foundations under a moving load. J. Sound Vib., 2012; 331, 2426-2442. doi: 10.1016/j.jsv.2011.12.036

[29] Abdelghany S.M., Ewis K.M., Mahmoud A.A., Nassar M. M. Dynamic response of non-uniform beam subjected to moving load and resting on nonlinear viscoelastic foundation. Journal of basic and applied siences, 2015; 4:192-199. doi: 10.1016/j.bjbas.2015.05.007

[30] Fallah. A, Aghdam. M. M. Thermo-mechanical buckling and nonlinear free vibration analysis of functionally graded beams on nonlinear elastic foundation. Composites Part B: Engineering. 2012; 43:1523-1530. doi: 10.1016/j.compositesb.2011.08.041

[31] Simsek. M. Nonlinear static and free vibration analysis of microbeams based on the nonlinear elastic foundation using modified couple stress theory and He's variational method. Composite structures, 2014; 112: 264-272. doi: 10.1016/j.compstruct.2014.02.010

[32] Simsek, M. Size dependent nonlinear free vibration of an Axially Functionally Graded (AFG) micro beam using He's variational method. Composite structures, 2015; 131: 207-214. doi: 10.1016/j.compstruct.2015.05.004

[33] Ansari. R. Ashrafi. M. A. Pourashraf. T. Hemmatnezhad. M. Vibration analysis of a postbuckled microscale FG beam based on modified couple stress theory. Shock and vibration, 2014; 654640. doi: 10.1155/2014/654640

[34] Emam S.A., Nayfeh A.H. Postbuckling and free vibrations of composite beams. Composite Structures, 2009; 88: 636-642. doi: 10.1016/j.compstruct.2008.06.006

[35] Soltani. M. Asgarian. B. Mohri. F. Elastic instability and free vibration analysis of tapered thin-walled beams by the power series method. Journal of constructional steel. 2014; 96: 106- 
126. doi: 10.1016/j.jcsr.2013.11.001

[36] Emam SA. A static and dynamic analysis of the postbuckling of geometrically imperfect composite beam. Composite Structures, 2009; 90: 247-253. doi: 10.1016/j.compstruct.2009.03.020

[37] He, J-H. Variational approach for nonlinear oscillators. Chaos, Solitons \& Fractals, 2007; 34(5): 1430-1439. doi: 10.1016/j.camwa.2009.03.074 